\title{
Carbon Fiber as Anode Material for Cathodic Prevention in Cementitious Materials
}

\author{
Emma Qingnan Zhang and Luping Tang \\ Department of Civil and Environmental Engineering, Chalmers University of Technology \\ Thomas Zack \\ Department of Earth Sciences, University of Gothenburg
}

\begin{abstract}
Cathodic prevention (CPre) technique is a promising method and has been used for the past two decades to prevent steel from corrosion in concrete structures. However, wide application of this technique has been restricted due to high costs of anode materials. In order to lower the cost and further improve this technique, carbon fiber composite anode has been introduced as an alternative anode material with affordable price and other outstanding properties. This paper presents the study of using carbon fiber mesh as anode material for long-term cathodic prevention system and the effect of accelerated current on macro- and microstructure of cementitious materials. In the study, electrochemically accelerated tests were developed for the purpose of shortening the experimental time into a manageable range. An estimation tool was used to predict the service life as well. Chemical and microstructure analyses were carried out by laser-ablation inductively-coupled-plasma mass-spectroscopy (LA-ICP-MS) and scanning electron microscope (SEM). Results indicate that calcium to silicon (Ca/Si) ratio and ion re-distribution in the current-affected zone around the anode were changed due to migration and electrochemical reactions. The predicted service life was in general longer than 100 years. Based on the results from this work, it can be concluded that carbon fiber mesh is suitable for the application as anode in long-term cathodic prevention system in cementitious materials.
\end{abstract}

Keywords: cathodic prevention, carbon fiber anode, LA-ICP-MS, SEM, electrochemical accelerated test, service life

\section{INTRODUCTION}

Corrosion of steel reinforcement is one of the major causes of damage or deterioration of reinforced concrete structures. Conventionally, to prevent reinforcement from corrosion, low water-cement ratio $(\mathrm{w} / \mathrm{c})$ is used in concrete for reducing ingress rate of aggressive substances and large cover thickness is designed for prolonging the time for aggressive substances to reach the reinforcement steel under a specified service life. Obviously, these conventional approaches are at the sacrifice of more $\mathrm{CO}_{2}$ emission and natural resources, which is against the fundamental ideas of sustainability. Therefore, new and more sustainable approaches are needed for corrosion prevention or protection of reinforcement steel in concrete structures. Because concrete is porous and contains electrolytic pore solution, using the principle of electrochemistry is probably an active way for prevention of reinforcement in concrete from corrosion. In such an approach the properties of concrete with a relatively high watercement ratio may be better utilized.

Based on the principle of electrochemistry, cathodic protection and prevention is now well-accepted as a powerful and efficient method for reducing corrosion rate and improve corrosion resistance of reinforcing steel in concrete (Bertolini, Bolzoni, Pedeferri, Lazzari, \& Pastore, 1998). Impressed current cathodic protection (ICCP) is achieved by means of an anode system usually laid on the concrete surface and connected with the positive terminal of a direct voltage source, while reinforcement acting as cathode and connected with the negative terminal. By shifting the electrical potential negatively the reinforcements are forced into passivity or immunity state. In some cases, cathodic protection measure is called "cathodic prevention" when it is applied on new structures that are expected to become contaminated by chloride during their service life. A small cathodic polarization of the steel should be applied on in the beginning of the service life. The current density for cathodic protection is $2-20 \mathrm{~mA} / \mathrm{m}^{2}$ of steel surface and for prevention it is 0.2-2 mA/m² (ISO-12696 2012, 2012).

Conventional cathodic protection technique of steel reinforcement in concrete structures has been proved to be efficient and effective (Ahmad, 2006; Pedeferri, 1996). Many papers have reported on case studies and practical experience (Chadwich, 1997; Polder, 1998; Schreyer, 1997; Virmani \& Clemena, 1998). The electrochemical reactions happened at cathode and anode depends on the environment, such as the 
diffusivity of oxygen and exposure conditions. The primary reactions are, for example:

- Primary reaction at cathode (rebar): $\mathrm{O}_{2}+2 \mathrm{H}_{2} \mathrm{O}+4 \mathrm{e}^{-} \rightarrow 4 \mathrm{OH}^{-}$

- Primary reaction at anode: $2 \mathrm{H}_{2} \mathrm{O} \rightarrow \mathrm{O}_{2}+4 \mathrm{H}^{+}+4 \mathrm{e}^{-}$;

- If in the presence of chlorides, chlorine develops: $2 \mathrm{Cl}^{-} \rightarrow \mathrm{Cl}_{2} \uparrow+2 \mathrm{e}^{-}$.

However, due to the nature of electrochemical reactions cathodic protection may also present some side-effects, i.e., (1) hydrogen embrittlement due to overprotection which is very sensitive to pre-stressed steel (Enos, Williams, \& Scully, 1997), (2) anode degradation or loss of adhesion between anode and concrete due to acid formation (Peelen, Polder, Redaelli, \& Bertolini, 2008), and (3) risk of alkalisilica reaction in case of the presence of reactive aggregates due to higher concentration of $\left[\mathrm{OH}^{-}\right]$in the pore solution (Orellan, Escadeillas, \& Arliguie, 2004; Sergi, Page, \& Thompson, 1991). Besides the high costs of anode materials and complex monitoring system, the service life of cathodic protection system is not very satisfactory yet. The average service life of CP system is around 20 years and at the time of 15 years maintenance is required (Polder, Leegwater, Worm, \& Courage, 2013).

Anode system as a key component in cathodic protection and prevention system has great impact on the performance and durability of the system. Mixed-metal oxide titanium (MMO/Ti) anodes have gained great acceptance for $\mathrm{CP}$ applications for the high current capacity, light weight, and low consumption rate (Heidersbach, Brandt, Johnson, \& Smart, 2006). However, their extensive use was restricted due to their high costs (Dreyman, 1972). Polymer composites anodes, especially carbonpolymer composites, as an attractive alternative have nowadays shown great potential as for its affordable costs, good electrical properties, and versatility in manufacture. Carbon-based material, as being considered the material of future technology, has drawn great attention and been under extensive study. Graphite conductor embedded polymer anodes have been used for cathodic prevention application for coastal reinforced concrete structures (Heidersbach et al., 2006). Conductive coating overlay containing graphite or carbon fiber reinforced cement has been verified to be suitable to use in cathodic protection system (Bertolini, Bolzoni, Pastore, \& Pedeferri, 2004; Darowicki, Orlikowski, Cebulski, \& Krakowiak, 2003; Jing \& Wu, 2011). It has been reported that $\mathrm{TiO}_{2}$ nanoparticles and graphene nanoplatelets can successfully be electrophoretically co-deposited onto stainless steel and provide sufficient negative potential shift (from $-0.4 \mathrm{~V}_{\text {SCE }}$ to $-0.7 \mathrm{~V}_{\text {SCE }}$ ) when exposed to UV light (Park \& Park, 2014).

However, studies of carbon fiber composites as anode for CP/CPre system are relatively new (Mahdi, 2010; Mayer, 2004). Mork, Mayer, and Rosenbom (2006) found that carbon fiber net anode showed no loss of weight and no defects when the system was applied to polarization voltage up to $1.8 \mathrm{~V}$ and the protection current is $1-2 \mathrm{~mA} / \mathrm{m}^{2}$. Mahdi (2010) reported in his doctoral thesis that carbon fiber composite can be used as anode material in cathodic protection or prevention systems and the polarization potential should not be above $300 \mathrm{mV}$. Above this value, the functioning life of the system might be estimated based on the weight loss of the carbon fiber net (Polder \& Peelen, 2011). In a technical report, Mork, Mayer, and Åsheim (2007) also monitored and investigated a harbor structure in Honningsvaag in Norway. The anode system consisted of carbon fiber meshes and cement-based mortar and the CP system was achieved by a current density of $2-5 \mathrm{~mA} / \mathrm{m}^{2}$ and a voltage of maximum $1.8 \mathrm{~V}$. The system was functioning well according to European standard EN 12696 at the day of their publishing.

Since studies of carbon fiber composites as anode material are relatively rare and only limited experiments have been carried out to discover the functionality of carbon fiber anode in CP system, this study aimed to examine the effect of applied current on carbon fiber anode and cementitious materials. The impact of accelerated current on microstructures of cementitious materials and preliminary method for service life prediction will be highlighted. The conclusions will be underlined as well.

\section{EXPERIMENTAL SET-UP}

\subsection{Carbon fiber mesh anode}

Carbon fiber composite mesh was used as anode in the experiment. The carbon fiber meshes was supplied by SGL Group, commercially named as SIGRATEX Grid 300. The dimension of the mesh was $25 \mathrm{~mm} \times 25 \mathrm{~mm}$ (inner space), containing two fiber threads in one direction and one fiber thread in another direction, with about $2 \mathrm{~mm}$ width per thread. Carbon fiber mesh anodes were cast inside the specimen. For paste specimens, a single fiber thread was used as anode instead of the grid.

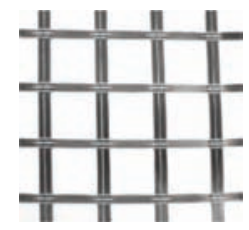

Figure 1. Carbon fiber mesh grid (SIGRATEX Grid 300) as anode material. 


\subsection{Service life model for anode}

In order to perform long-term (100 years) cathodic prevention analysis, an accelerated test method must be developed to shorten the experimental time. The concept of electrochemically accelerated test is to increase the current density applied to the system in order to shorten the total testing period into a manageable length. The total amount of electrons applied into the system is defined as a polarization parameter $\Phi$ (Chang, 2002).

$$
\Phi=I_{\text {applied }} \times t_{\text {applied }}
$$

where $\Phi$ is the total amount of electrical charge applied to the system during the entire period of acceleration test. $\left(\mathrm{C} / \mathrm{m}^{2}\right.$, where $\mathrm{C}$ is abbreviation for Coulomb), $I_{\text {applied }}$, the applied current density into the system $\left(\mathrm{A} / \mathrm{m}^{2}\right), t_{\text {applied }}$, the time that the applied current density is available (seconds).

To estimate the service life of anode system by using electrochemical acceleration method, the general principle is as following:

$$
\Phi=I_{a} \times t_{a}=I_{e} \times t_{e}
$$

So that the equivalent time $t_{e}$ at a typical current density for cathodic prevention can be rearranged as following:

$$
t_{e}=\frac{l_{a}}{l_{e}} \cdot t_{a}
$$

where $\Phi$ is the same as in Eq. (1), but the unit can be expressed as ( $\mathrm{mA} \cdot \mathrm{m}^{-2}$ days) for convenience in engineering practice, $l_{a}$, the applied current density in accelerated tests $\left(\mathrm{mA} / \mathrm{m}^{2}\right), t_{a}$, the accelerated testing period, which is 60 days if not elsewhere stated, $I_{e}$, typical current density of cathodic prevention $\left(0.2^{e^{\prime}}\right.$ $2.0 \mathrm{~mA} / \mathrm{m}^{2}$ ), where in this test the upper limit $2.0 \mathrm{~mA} / \mathrm{m}^{2}$ is chosen for estimation the service life in real case $\left(\mathrm{mA} / \mathrm{m}^{2}\right), t_{e}$, the estimated equivalent service life of cathodic prevention system in the real case (days).

For example, when the polarization parameter $\Phi$ is $2000\left(\mathrm{~mA} \cdot \mathrm{m}^{-2}\right.$ days), if a cathodic prevention current $2 \mathrm{~mA} / \mathrm{m}^{2}$ is used as in engineering practice, then the predicted service life is 1000 days (2.7 years).

\subsection{Experimental program}

The testing program was divided mainly into two parts: group of paste specimens, coded as ACC_P, and group of mortar specimens, coded as ACC_M. All specimens were treated in accelerated tests with different current densities for a certain period of time. Paste specimens were designed to investigate chemical and microstructure properties, and mortar specimens were designed to examine the equivalent service life.

\subsection{Specimens}

Water binder ratio 0.6 was used for all paste and mortar specimens. For paste specimens, only Portland cement was used. For mortar specimens, fly ash were added to replace $20 \%$ of cement content and ground granulated blast-furnace slag (GGBS) were added to replace $25 \%$ of cement content.

Plain steel reinforcement was chosen as cathode. Anode material was carbon fiber mesh. Both cathode and anode were cast inside directly with cement or mortar. The dimension of paste specimen was $40 \mathrm{~mm} \times 40 \mathrm{~mm} \times 160 \mathrm{~mm}$ and mortar specimen $50 \mathrm{~mm} \times 200 \mathrm{~mm} \times 300 \mathrm{~mm}$. In consideration of the feasibility of conducting microstructural tests, a single fiber thread was used as anode in a paste specimen. For mortar specimen, mesh grid as received was used. The positions of anode and cathode were the same for all specimens, which was $5 \mathrm{~mm}$ between anode and exposure surface and $15 \mathrm{~mm}$ between anode and cathode.

In accelerated tests, specimens were partially immersed in a $10 \% \mathrm{NaCl}$ solution and connected to external power supply. Except the exposure surface (with cover of $5 \mathrm{~mm}$ to the carbon fiber anode), other surfaces were coated by epoxy resin to prevent unwanted chloride migration.

\subsection{Electrochemically accelerated tests}

\subsubsection{Paste specimen group}

Paste group ACC_P had three specimens that were connected to different currents and one control specimen which was not connected to any power supply as reference. The reinforced steel bars were connected to the negative terminal of the external power supply acting as cathode and the carbon fiber mesh anode to the positive terminal. Test period was 60 days. Absolute coulomb value, current density of immersed steel, and estimated equivalent service life were presented in Table 1.

Table 1. Accelerated tests of paste specimen group.

\begin{tabular}{lrrr}
\hline Paste group & ACC_P1 & ACC_P2 & ACC_P3 \\
\hline Absolute coulomb value (C) & 26,044 & 32,556 & 97,667 \\
$\begin{array}{l}\text { Current density of wet steel } \\
\left(\mathrm{mA} / \mathrm{m}^{2}\right)\end{array}$ & 800 & 1538 & 4615 \\
Equivalent service life (years) & 66 & 123 & 360 \\
\hline
\end{tabular}

\subsubsection{Mortar specimen group}

There were two parts of experiments in mortar specimen group, as part ACC_M1 and part ACC_M2. The purpose of these two experiments was different. For ACC_M1, the anode-mortar interface and surface condition were monitored under the entire designed test period (30 and 60 days), while for ACC_M2, 
acceleration time was recorded until damage occurred on the specimen or the CPre system was failed. The applied current density and estimated service life were shown in Table 2 and 3.

Table 2. Applied current density and estimated service life of ACC_M1.

\begin{tabular}{lr}
\hline Description & Value \\
\hline Applied constant current $(\mathrm{mA})$ & 60 \\
Current density of wet steel $\left(\mathrm{mA} / \mathrm{m}^{2}\right)$ & 4777 \\
Acceleration time (days) & 30 \\
Equivalent service life (years) & 196 \\
Acceleration time (days) & 60 \\
Equivalent service life' (years) & 393 \\
\hline
\end{tabular}

Table 3. Applied current density of ACC_M2.

\begin{tabular}{lr}
\hline Description & Value \\
\hline Applied constant current $(\mathrm{mA})$ & 40 \\
Current density of wet steel $\left(\mathrm{mA} / \mathrm{m}^{2}\right)$ & 3185
\end{tabular}

\section{ANALYTICAL METHODS}

\subsection{Laser ablation-inductively coupled plasma-mass spectroscopy (LA-ICP-MS)}

The chemical analysis of treated specimen was carried out by Laser Ablation analysis at the University of Gothenburg using a New Wave NWR213 laser ablation system coupled to an Agilent 7500 a quadrupole ICP-MS (upgraded with shield torch and a second rotary vacuum pump). A Large Format Cell holds samples up to $10 \mathrm{~cm} \times 10 \mathrm{~cm}$ in size, combined with a $1-\mathrm{cm}$ diameter ablation chamber at the ablation region, enabling fast washout anywhere in the sample chamber. A 30- $\mu \mathrm{m}$ laser spot size, beam energy density of about $6 \mathrm{~J} / \mathrm{cm}^{2}$ and repetition rate of $10 \mathrm{~Hz}$ was used in line scan mode (scan speed 60 or $100 \mu \mathrm{m} / \mathrm{s}$ ). The sample and ablation chamber were flushed with helium to carry the aerosol produced during ablation to the ICP-MS. Before reaching the torch, the carrier gas was mixed with argon and nitrogen. Each measurement consisted of $30 \mathrm{~s}$ background followed by $100-200 \mathrm{~s}$ of signal collection. Dwell times are $10 \mathrm{~ms}$ for masses analyzed $\left({ }^{13} \mathrm{C},{ }^{23} \mathrm{Na},{ }^{24} \mathrm{Mg},{ }^{27} \mathrm{Al},{ }^{28} \mathrm{Si}\right.$ or ${ }^{29} \mathrm{Si},{ }^{34} \mathrm{~S}$, ${ }^{35} \mathrm{Cl},{ }^{39} \mathrm{~K},{ }^{43} \mathrm{Ca},{ }^{47} \mathrm{Ti},{ }^{55} \mathrm{Mn}$, and $\left.{ }^{57} \mathrm{Fe}\right)$. Quantification was performed by frequently measuring the glass standard SRM NIST 610 using values by Jochum et al. (2011). Variations in calculated abundances of all measured isotopes (except for $\mathrm{C}, \mathrm{S}$, and $\mathrm{Cl}$, which are too low to be quantified in SRM NIST 610) were $<10 \%$ throughout a whole analytical session. A schematic diagram of LA-ICP-MS instrument is shown in Figure 2.

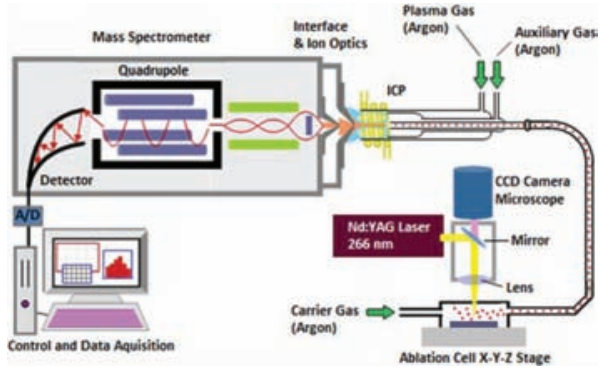

Figure 2. A schematic diagram of LA-ICP-MS technique (Silva, Tang, \& Rauch, 2013).

\subsection{Scanning electron microscope (SEM)}

The chemical composition and surface image analysis were carried out at University of Gothenburg by a Hitachi S-3400N Variable Pressure SEM integrated with energy-dispersive spectrometer (EDS). Accelerating voltage was $20 \mathrm{kV}$. Detection limits were about $0.1 \%$ with EDS (1000 ppm). Backscattered electron (BSE) mode was used to examine cement paste samples.

\section{RESULTS AND DISCUSSIONS}

\subsection{Microstructure study on control sample}

A carbon fiber thread from mesh imbedded in cement paste without electrochemical acceleration treatment was used as a control sample to investigate the chemical composition without the effect from external electrical field. The control sample was also partially submerged in a $10 \%$ sodium chloride solution. A SEM image of the control sample was shown in Figure 3. The semi-quantitative analysis of chemical composition of the control sample by LA-ICP-MS was listed in Table 4, as a baseline of specimens without any electrochemical treatment. The calcium silica mole ratio $(\mathrm{Ca} / \mathrm{Si})$ of the control sample was around 3 , shown in Figure 4. In comparison with the chemical analysis of clinker compositions (provided by cement manufacturer CEMENTA), chemical analysis from LA-ICP-MS has shown good precision. The high concentration of sodium and chloride were due to the diffusion of ions from the immersion solution into the sample.

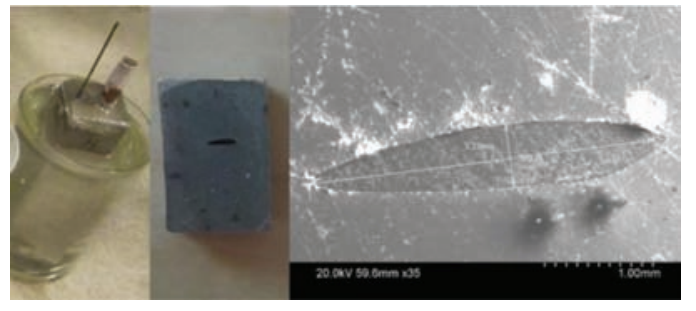

Figure 3. Cross-section of the control sample and dimension of a carbon fiber thread under SEM. 
Table 4. Chemical composition analysis from LA-ICP-MS technique and from manufacturer's value.

\begin{tabular}{lcc}
\hline Composition & $\begin{array}{c}\text { LA-ICP-MS } \\
\text { analysis }\end{array}$ & $\begin{array}{c}\text { Clinker composition } \\
\text { (wt\%) }\end{array}$ \\
\hline $\mathrm{CaO}$ & 64 & 63.7 \\
$\mathrm{SiO}_{2}$ & 24 & 22.0 \\
$\mathrm{Al}_{2} \mathrm{O}_{3}$ & 3.5 & 3.7 \\
$\mathrm{Fe}_{2} \mathrm{O}_{3}$ & 3.0 & 4.3 \\
$\mathrm{MgO}$ & 0.23 & 1.1 \\
$\mathrm{Na}_{2} \mathrm{O}$ & $2.2^{1}$ & 0.07 \\
$\mathrm{~K}_{2} \mathrm{O}$ & 0.3 & 0.69 \\
$\mathrm{SO}_{3}$ & - & 2.5 \\
$\mathrm{Cl}$ & $3.4^{1}$ & 0.01 \\
\hline
\end{tabular}

${ }^{1}$ Concentration of $\mathrm{Na}$ and $\mathrm{Cl}$ is increased because of ion diffusion from $10 \% \mathrm{NaCl}$ solution, which is not comparable with those values from clinker composition.

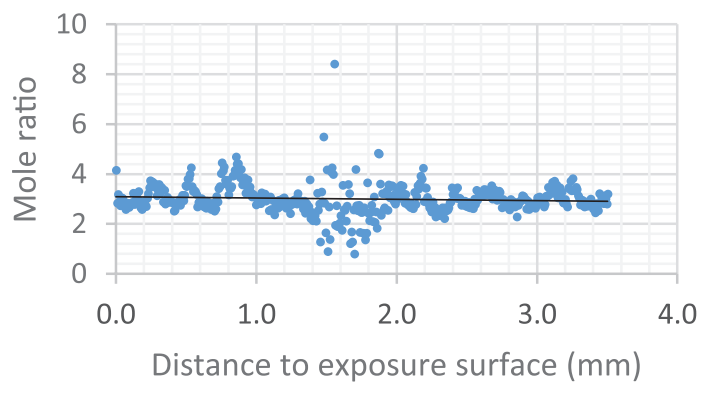

Figure 4. $\mathrm{Ca} / \mathrm{Si}$ mole ratio is around 3 in the control sample. At distance $1.5-2 \mathrm{~mm}$ is the location of carbon fiber anode.

\subsection{Compositional changes and ion re-distributions in the anode zone}

After 2-month period of accelerated test, specimens were taken out, sawed into slice. The ring-pattern around the carbon fiber anode was found, as shown in Figure 5. The back-scattered SEM image also confirmed that the ring-pattern area has different phases as it is layered, as shown in Figure 6. The dimension of the affected zone is from 0.5 to $2 \mathrm{~mm}$ around the anode.

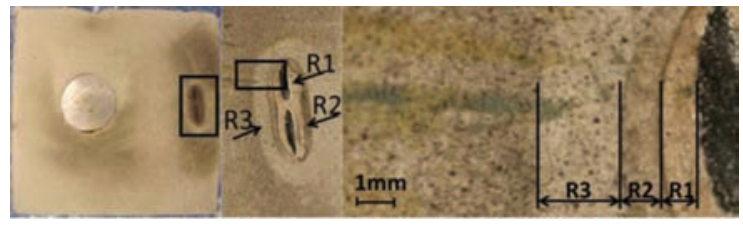

Figure 5. Sawed samples (left), ring-pattern (middle), and the dimension of the ring-pattern (right). Dimension of the ring-pattern is around 1-2 mm (specimen ACC_P1, equivalent service life is 132 years).

A change in the $\mathrm{Ca} / \mathrm{Si}$ ratio in the vicinity of anode was observed by both the SEM and LA-ICP-MS measurements. SEM results showed that $\mathrm{Ca} / \mathrm{Si}$ ratio was decreased in the zone close to anode compared with the $\mathrm{Ca} / \mathrm{Si}$ ratio in paste matrix, while $\mathrm{Na} / \mathrm{Si}$ ratio was increased (see Table 5). The same trend was observed by measuring the concentration of each element by LA-ICP-MS (see Figures 7 and 8 ). Results

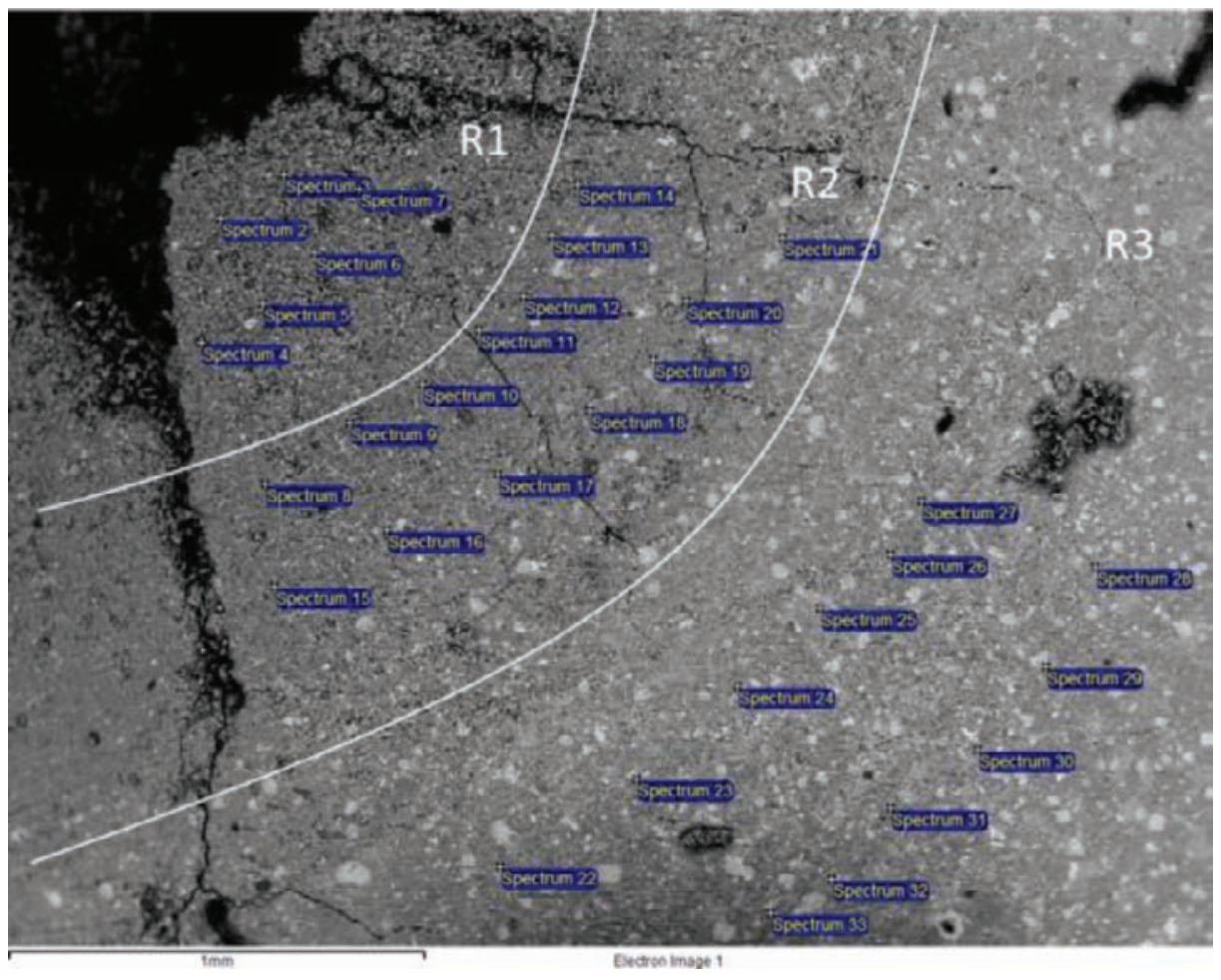

Figure 6. Back-scattered SEM image of the ring-pattern area, shown different phases of the ring-pattern area around anode. The crack through the ring area was formed after experiment due to drying. (specimen ACC_P2, equivalent service life 123 years). 


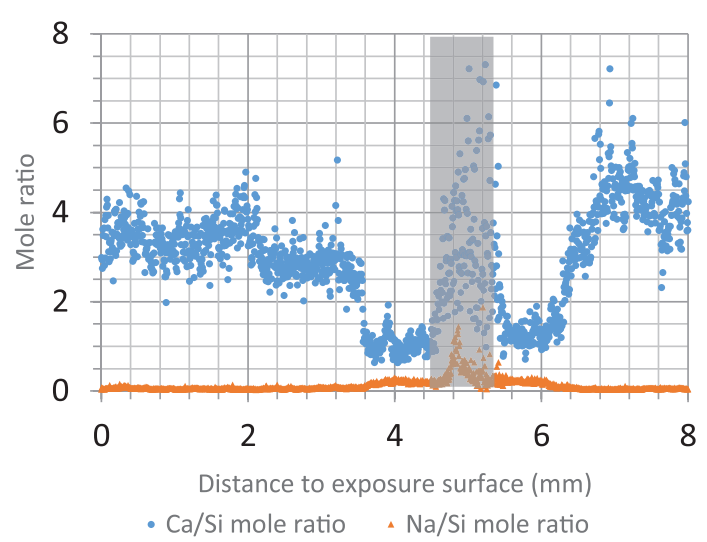

Figure 7. (ACC_P1, 66 years of equivalent service life) Line scanning by LA-ICP-MS across the cross-section of accelerated specimen. The shadowed area indicates the position of carbon fiber anode.

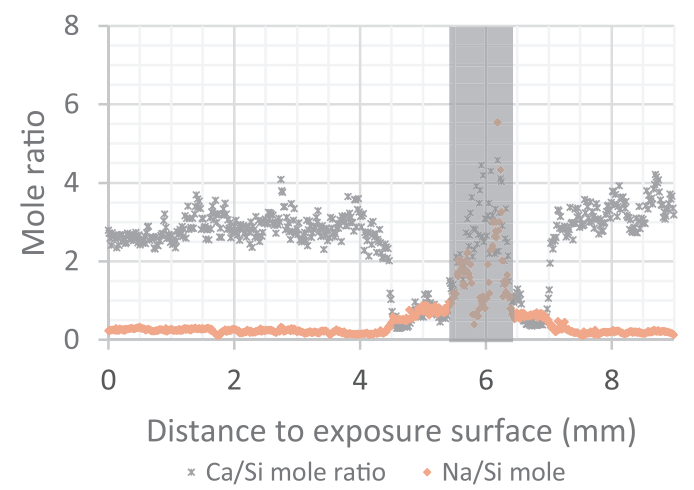

Figure 8. (ACC_P3, 360 years of equivalent service life) Line scanning by LA-ICP-MS across the cross-section of accelerated specimen. The shadowed area indicates the position of carbon fiber anode.

indicate that in the area close to the carbon fiber anode, the concentration of $\mathrm{Ca}$ was lower than that in the cementitious matrix. This phenomenon is due to the ion migration under the feeding potential, under which the positive $\mathrm{Ca}^{2}+$ in the pore solution [dissolved from portlandite, $\mathrm{Ca}(\mathrm{OH})_{2}$ ] has been migrated away from the anode. Due to the nature of $\mathrm{C}-\mathrm{S}-\mathrm{H}$ gel, the distribution of silicon in the cement paste matrix is assumed unchanged because the $\mathrm{Si}-\mathrm{O}$ bonding is very stable and hardly to be broken or reformed even under strong acid environment at a high temperature (Ryu, Otsuki, \& Minagawa, 2002). Therefore, the changes of $\mathrm{Ca} / \mathrm{Si}$ ratio can be considered as the changes of calcium in the cement paste matrix.

Table 5. Spot analysis of paste specimen ACC_P1 and ACC_P2.

\begin{tabular}{lcccc}
\hline & \multicolumn{2}{c}{ ACC_P1 } & \multicolumn{2}{c}{ ACC_P2 } \\
\cline { 2 - 5 } Average & Ca/Si ratio & Na/Si ratio & Ca/Si ratio & Na/Si ratio \\
\hline Ring-1 & $2: 3$ & $0: 5$ & $2: 6$ & $0: 2$ \\
Ring-2 & $3: 0$ & $0: 1$ & $3: 5$ & $0: 1$ \\
Ring-3 & $4: 7$ & $0: 1$ & $5: 9$ & $0: 1$ \\
\hline
\end{tabular}

Lower Ca/Si ratio was found in ACC_P3 compared to that in ACC_P1, shown in Figure 9, which indicates more calcium ions migrated away from anode under the effect of accelerated current. Severe calcium migration can be expected to happen under stronger current density, although the diameter of the effect zone around anode was limited around $1 \mathrm{~mm}$ range.

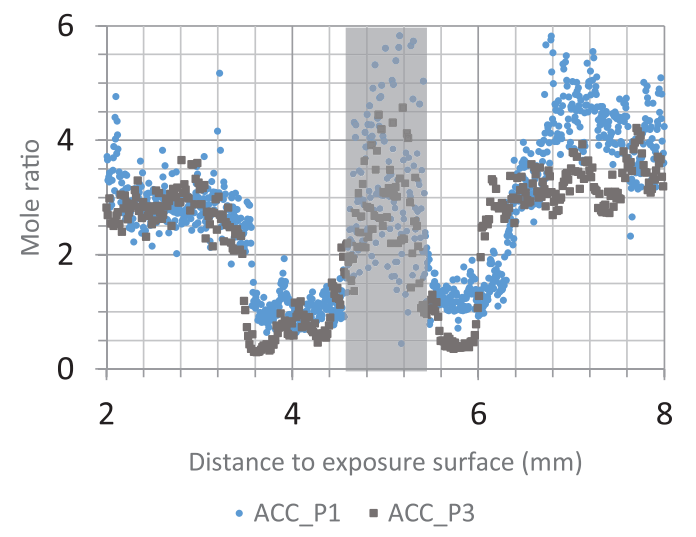

Figure 9. $\mathrm{Ca} / \mathrm{Si}$ ratio of specimen $\mathrm{ACC}$ P 1 and $\mathrm{ACC}$ P 3 . The shadowed area indicates the position of carbon fiber anode.

On the other hand, positive ions sodium $\left(\mathrm{Na}^{+}\right)$did not show the same movement as calcium. The mole concentration of sodium reached a peak and then gradually decreased to a base level. The possible explanation might be as follows. Under the electrochemical treatment, the hydrogen ions were formed around the anode from the electrolysis of water. These hydrogen ions $\left(\mathrm{H}^{+}\right)$produced locally acidic condition which dissolved portlandite. The dissolved calcium ions moved away from the zone around the anode, forming rings with lower ratios of $\mathrm{Ca} / \mathrm{Si}$, as discussed above. After termination of the electrochemical treatment, sodium ions which have relatively higher diffusivity and less binding with $\mathrm{C}-\mathrm{S}-\mathrm{H}$ than calcium ions diffused from the surrounding cement paste matrix back to the zones around the anode to neutralize the negatively charged zone, resulting in peaks of $\mathrm{Na} / \mathrm{Si}$ around the anode, as shown Figure 8.

SEM analysis also found $\mathrm{NaCl}$ crystals at the anode and in the ring-pattern affected area. In Figure 10, the white substances (left) are confirmed as $\mathrm{NaCl}$ crystals (right). LA-ICP-MS analysis has detected high concentration of $\mathrm{NaCl}$ in the anode area but not in the ring-pattern affected area, as shown in Figure 11. This is probably due to sample preparation of SEM analysis. After careful surface polishing, substances in the ringpattern affected area and the anode area could move around, because they are relatively loose, while sample polishing for LA-ICP-MS is very brief and fast. 


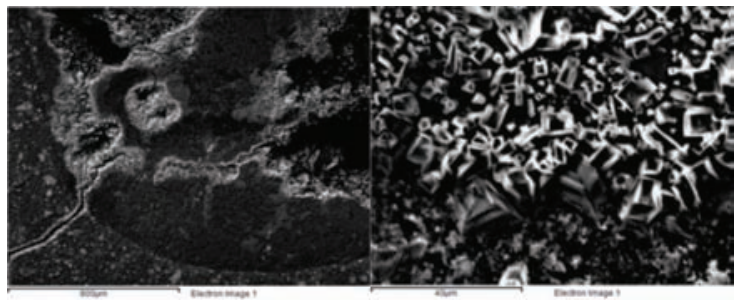

Figure 10. (ACC_P3, equivalent service life 360 years) Sodium chloride crystals at anode and ring-pattern effected area.

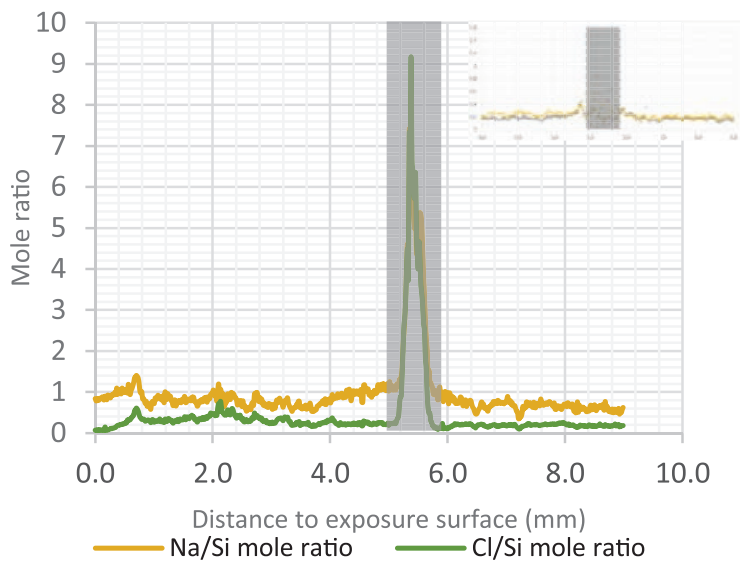

Figure 11. (ACC_P3, equivalent service life 360 years) High concentration of sodium and chloride at anode area. The shadowed area indicates the position of carbon fiber. Figure in the corner showed concentration of sodium and chloride on control sample, which indicated no significant sodium and chloride at anode area.

Precipitation of $\mathrm{NaCl}$ at the anode can be considered as a preventative effect of hindering chloride further migrating towards steel reinforcement. However, higher concentration of chloride might promote the production of chlorine gas which has potential risk of inducing internal cracks and hazard issue.

\subsection{Surface condition of mortar specimens}

The current density used for part ACC_M1 was about $5 \mathrm{~A} / \mathrm{m}^{2}$ that is much higher than typical prevention current density, which is normally in the range of $0.2-2 \mathrm{~mA} / \mathrm{m}^{2}$. So, here it is worth to point out that the surface damage in the accelerated test should be worse than that under typical prevention current density. In other word, if the same level of surface damage would be reached under normal prevention current densities, the time it took should be longer than the estimated equivalent service life.

After 30 days acceleration test (equivalent to 196 years of service life), surface damage was observed on specimens A (OPC) and C (PC $+25 \%$ GGBS) at the position below and along the immersion line (see Figure 12). Specimen B (PC $+20 \% F A)$ still revealed good surface condition, indicating that fly ash additive has better homogeneity than slag. Figure 13 shows the specimen with the same mix after 60 days acceleration test (equivalent to 393 years of service life). All three specimens had surface damage along the immersion line, which indicated the area around immersion solution, as in the real case as the tidal zone, can be considered as critical area because of higher risk of damage.

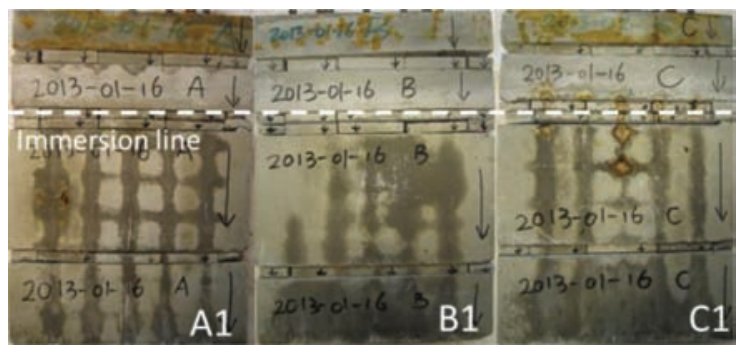

Figure 12. Group ACC_M1 specimen A1 to C1 after accelerated test. Specimen A - OPC; B - PC+20\%FA; C - PC+25\%GGBS. Designed equivalent service life is 196 years.

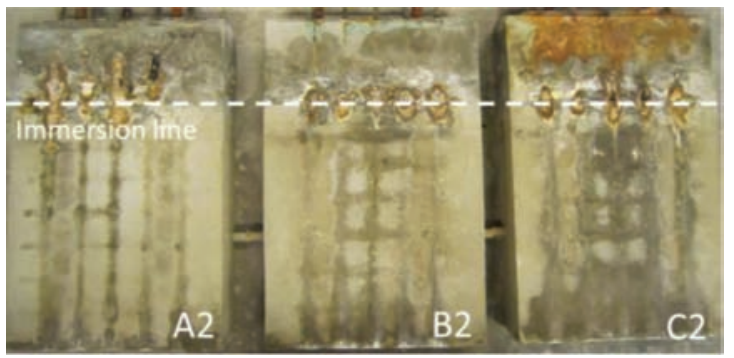

Figure 13. Group ACC_M1 specimen $A 2$ to $C 2$ after accelerated test. Specimen A - OPC; B - PC+20\%FA; C - PC+25\%GGBS. Designed equivalent service life is 393 years.

\subsection{Equivalent service life of mortar specimens}

For part ACC_M2, the applied current density was about $3 \mathrm{~A} / \mathrm{m}^{2}$ for specimen \#1, \#2, and \#3 and for specimen \#4 and \#5 the current densities were reduced to 50 and $25 \%$, respectively. Two criteria were used to determine the service life of each specimen. One was based on the surface condition, i.e., the experiment was terminated when the surface damage was observed, e.g., specimens \#1, \#3, \#4, and \#5, as shown in Figure 14. Another criterion was dependent on the actual applied current without showing any apparent surface damage. As in the case of specimen $\# 2$, the experiment was terminated when the actual

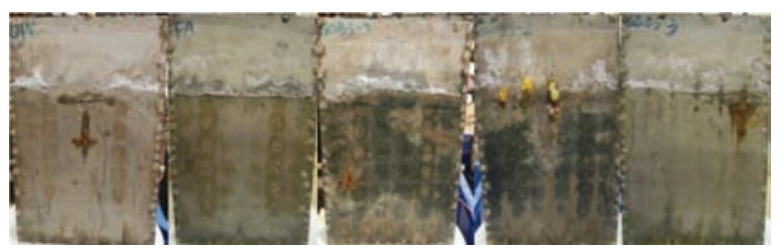

Figure 14. Mortar group ACC_M2 after acceleration test. \#1 - OPC, equivalent 118 years; \#2 - PC + 20\%FA, equivalent 297 years; $\# 3-P C+25 \%$ GGBS, equivalent 144 years; \#4 - PC + 25\%GGBS, equivalent 179 years; \#5 - PC + 25\%GGBS, equivalent 71 years. 
applied current density was lowered by $40 \%$ of the original designed value, indicating possible internal damage or disconnection due to dramatic decrease in ionic concentration near the anode.

As for the damage location, specimen \#4 and \#5 showed the surface damage along the immersion line, which were in agreement with ACC_M1 specimen A2, B2, and C2. However, specimen \#1 and \#3 had damage below the immersion line, probably due to the inhomogeneity of the mortar material, or defects such as air bubble, microcracks, and so on. Those internal defects or inhomogeneity can lead to locally higher current density causing earlier damage in the defected area.

Among specimen $\# 3, \# 4$, and $\# 5$, the expected service life should be increased as the current density was lowered. Specimen \#4 showed this trend but not specimen \#5. Since the number of specimens was limited, it is hard to conclude the relation between prolonged service life and lowered current density in this case. However, the trend is promising. As mentioned before, the inhomogeneity of the microstructure could also play an important role.

It is worth to point out that the surface damage only gives a poor esthetic appearance but should not jeopardize structural properties of the reinforced concrete, because the reinforcement steel is still prevented from corrosion once the cathodic polarization current can be imposed.

Table 6. Estimated equivalent service life of mortar group ACC_M2.

\begin{tabular}{|c|c|c|c|c|c|}
\hline Specimen & \#1 & \#2 & \#3 & \#4 & \#5 \\
\hline Mix design & OPC & $\begin{array}{c}20 \% \\
\text { FA }\end{array}$ & $\begin{array}{l}25 \% \\
\text { GGBS }\end{array}$ & $\begin{array}{l}25 \% \\
\text { GGBS }\end{array}$ & $\begin{array}{c}25 \% \\
\text { GGBS }\end{array}$ \\
\hline $\begin{array}{l}\text { Testing time until } \\
\text { interruption (days) }\end{array}$ & $27^{1}$ & $68^{2}$ & $33^{1}$ & $82^{1}$ & $65^{1}$ \\
\hline Applied current (mA) & 40 & 40 & 40 & 20 & 10 \\
\hline Current density $\left(\mathrm{A} / \mathrm{m}^{2}\right)$ & 3.2 & 3.2 & 3.2 & 1.6 & 0.8 \\
\hline $\begin{array}{l}\text { Absolute coulomb } \\
\text { value }\left(C \times 10^{4}\right)\end{array}$ & 10.9 & 22.4 & 10.9 & 14.4 & 5.9 \\
\hline $\begin{array}{l}\text { Equivalent service life } \\
\text { (years) }\end{array}$ & 118 & 297 & 144 & 179 & 71 \\
\hline
\end{tabular}

${ }^{1}$ Terminated due to apparent surface damage.

${ }^{2}$ Terminated due to low prevention current density.

\section{CONCLUSION}

This study aimed at evaluating carbon fiber mesh as anode material for long-term cathodic prevention system and investigating the effect of accelerated current on macro- and microstructure of cementitious materials. Based on the experimental results and analyses, some general conclusions can be drawn as follows.
- Carbon fiber mesh is suitable for the application of cathodic prevention system for steel reinforced concrete structures.

- The estimated equivalent service life is in general over 100 years.

- Electrochemically accelerated test can be used as a valuable tool to evaluate specimens in a shortterm equivalent to a long-term exposure and to estimate the service life conservatively.

- The electrochemically affected zone around anode is from 0.5 to $2 \mathrm{~mm}$ due to acidification and ion migration.

- Microstructural and chemical changes occurred at the anode-paste interface due to the imposed current.

- Inhomogeneity of cementitious materials plays an important role in current distribution and, as a consequence, damage starts at the point where current is concentrated.

\section{REFERENCES}

Ahmad, Z. (2006). Principles of corrosion engineering and corrosion control. Burlington, MA; Oxford, England: Butterworth-Heinemann.

Bertolini, L., Bolzoni, F., Pastore, T., \& Pedeferri, P. (2004). Effectiveness of a conductive cementitious mortar anode for cathodic protection of steel in concrete. Cement and Concrete Research, 34, 681-694.

Bertolini, L., Bolzoni, F., Pedeferri, P., Lazzari, L., \& Pastore, T. (1998). Cathodic protection and cathodic prevention in concrete: Principles and applications. Journal of Applied Electrochemistry, 28, 1321-1331.

Chadwich, Z. C. J. R. (1997). Cathodic protection of buried reinforced concrete structures. In J. Mietz, B. Elsener, \& R. Polder (Eds.), Corrosion of reinforcement in concrete Monitoring, prevention and rehabilitation: (EFC 25). Maney Publishing.

Chang, J. (2002). A study of the bond degradation of rebar due to cathodic protection current. Cement and Concrete Research, 32, 657-663.

Darowicki, K., Orlikowski, J., Cebulski, S., \& Krakowiak, S. (2003). Conducting coatings as anodes in cathodic protection. Progress in Organic Coatings, 46, 191-196.

Dreyman, E. W. (1972). Precious metal anodes-state of art. Materials Protection and Performance, 11, 17.

Enos, D., Williams, A., Jr., \& Scully, J. (1997). Longterm effects of cathodic protection on prestressed concrete structures: Hydrogen embrittlement of prestressing steel. Corrosion, 53, 891-908. 
Heidersbach, R. H., Brandt, J., Johnson, D., \& Smart, J. S., III (2006). Marine cathodic protection, corrosion: Environments and industries.

ASM Handbook (Vol. 13C, pp. 73-78). ASM International.

ISO-12696 2012. (2012). Cathodic protection of steel in concrete.

Jing, X., \& Wu, Y. (2011). Electrochemical studies on the performance of conductive overlay material in cathodic protection of reinforced concrete. Construction and Building Materials, 25, 2655-2662.

Jochum, K. P., Weis, U., Stoll, B., Kuzmin, D., Yang, Q., Raczek, I., ... Frick, D. A. (2011). Determination of reference values for NIST SRM 610-617 glasses following ISO guidelines. Geostandards and Geoanalytical Research, 35, 397-429.

Mahdi, C. (2010). Pan-based carbon fiber as anode material in cathodic protection systems for concrete structures. (Doctoral degree). Norwegian University of Science and Technology.

Mayer, S. (2004). Cathodic protection investigations into the effectiveness of a cathodic protection system for reinforced concrete specimens in order to optimize anode fields. (Diploma thesis). Munich University of Applied Science, Munich, Germany.

Mork, J. H., Mayer, S., \& Åsheim, R. (2007). The performance of cathodic protection on harbor and jetty of Honningsvåg Norway. Fifth International Conference on Concrete under Severe Conditions Environment and Loading (CONSEC 07). Tours, France.

Mork, J. H., Mayer, S., \& Rosenbom, K. (2006). Cathodic protection of concrete structures with a carbon fiber mesh anode. EUROCORR2006. Maastricht, The Netherlands.

Orellan, J., Escadeillas, G., \& Arliguie, G. (2004). Electrochemical chloride extraction: Efficiency and side effects. Cement and Concrete Research, 34, 227-234.
Park, J. H., \& Park, J. M. (2014). Photo-generated cathodic protection performance of electrophoretically co-deposited layers of $\mathrm{TiO} 2$ nanoparticles and graphene nanoplatelets on steel substrate. Surface and Coatings Technology, 258, 62-71.

Pedeferri, P. (1996). Cathodic protection and cathodic prevention. Construction and Building Materials, 10, 391-402.

Peelen, W., Polder, R., Redaelli, E., \& Bertolini, L. (2008). Qualitative model of concrete acidification due to cathodic protection. Materials and Corrosion, 59, 81-89.

Polder, R. B. (1998). Cathodic protection of reinforced concrete structures in The Netherlands-experience and developments. Book-Institute of Materials, 710, 172-183.

Polder, R. B., Leegwater, G., Worm, D., \& Courage, W. (2013). Service life and life cycle cost modelling of cathodic protection systems for concrete structures. Cement and Concrete Composites,.

Polder, R. B., \& Peelen, W. H. (2011). Service life aspects of cathodic protection of concrete structures. Abingdon, England: Taylor and Francis.

Ryu, J.-S., Otsuki, N., \& Minagawa, H. (2002). Long-term forecast of $\mathrm{Ca}$ leaching from mortar and associated degeneration. Cement and Concrete Research, 32, 1539-1544.

Schreyer, C. H. A. (1997). Ten years of cathodic protection in concrete in Switzerland. Corrosion of reinforcement in concrete - Monitoring, prevention and rehabilitation: (EFC 25). Maney Publishing.

Sergi, G., Page, C., \& Thompson, D. (1991). Electrochemical induction of alkali-silica reaction in concrete. Materials and Structures, 24, 359-361.

Silva, N., Tang, L., \& Rauch, S. (2013). Application of LA-ICP-MS for meso-scale chloride profiling in concrete. Materials and Structures, 46, 1369-1381.

Virmani, Y. P., \& Clemena, G. G. (1998). Corrosion protection-concrete bridges. 